\title{
FORUM
}

\section{Natural Invertebrate Hosts of Iridoviruses (Iridoviridae)}

\author{
TREVOR WiLliams \\ Instituto de Ecología A.C., Xalapa 91070,Veracruz, Mexico; trevor.williams@inecol.edu.mx \\ Neotropical Entomology 37(6):615-632 (2008)
}

Hospederos Naturales de los Iridovirus de Invertebrados

\begin{abstract}
RESUMEN - Los virus iridiscentes de invertebrados (VIIs) son virus icosaedrales de ADN que infectan a invertebrados, principalmente insectos e isópodos terrestres en hábitats húmedos y acuáticos. Búsquedas extensivas de bases de datos resultaron en la identificación de 79 artículos científicos, los cuales reportaron 108 especies de invertebrados infectados naturalmente por iridovirus. De estos, 103 (95\%) fueron artrópodos y los otros fueron moluscos, un anélido y un nematodo. Nueve especies fueron de hábitats marinos. De las 99 especies no marinas, 49 fueron terrestres y 50 fueron acuáticas, especialmente los estadios acuáticos de dípteros (44 especies). La abundancia de infecciones en especies de Aedes, Ochlerotatus y Psorophora se contrasta marcadamente con la escasez de casos en especies de Anopheles, Culex y Culiseta. Reportes de infecciones de los isópodos terrestres son numerosos (19 especies), aunque la diversidad de los VII que los infectan es desconocida. Se han reportado infecciones por VIIs de todos los continentes, excepto Antártica, pero se notan pocos ejemplos de África, Asia y Latinoamérica. La mayoría de los artículos señala que las infecciones patentes son poco comunes, mientras que las infecciones enmascaradas (subletales) pueden ser comunes en algunas especies. La relación entre el tamaño de la partícula y el color iridiscente concuerda con la teoría óptica en casi todos los casos. Veinticuatro de los VIIs de insectos han sido caracterizados parcialmente y solo dos de éstos han sido secuenciados completamente. Demuestro que el ritmo de publicación sobre los VIIs ha disminuido en los últimos 15 años, señalo varias conclusiones y sugerencias de la lista de especies de huéspedes y presento algunas recomendaciones para la investigación futura con este grupo de patógenos.
\end{abstract}

PALABRAS CLAVE: Abundancia, infección, huésped natural, tamaño de partícula, caracterización de virus

\begin{abstract}
Invertebrate iridescent viruses (IIVs) are icosahedral DNA viruses that infect invertebrates, mainly insects and terrestrial isopods, in damp and aquatic habitats. Exhaustive searches of databases resulted in the identification of 79 articles reporting 108 invertebrate species naturally infected by confirmed or putative iridoviruses. Of these, 103 (95\%) were arthropods and the remainder were molluscs, an annelid worm and a nematode. Nine species were from marine habitats. Of the 99 non-marine species, 49 were from terrestrial habitats and 50 were aquatic, especially the aquatic stages of Diptera (44 species). The abundance of records from species of Aedes, Ochlerotatus and Psorophora contrasts markedly with a paucity of records from species of Anopheles, Culex and Culiseta. Records from terrestrial isopods are numerous (19 species), although the diversity of IIVs that infect them is mostly unstudied. IIV infections have been reported from every continent, except Antarctica, but there are few records from Africa, southern Asia and Latin America. Most reports describe patent IIV infections as rare whereas inapparent (covert) infection may be common in certain species. The relationship between particle size and iridescent colour of the host is found to be consistent with optical theory in the great majority of cases. Only 24 reported IIVs from insect hosts have partial characterization data and only two have been subjected to complete genome sequencing. I show that the rate of publication on IIVs has slowed from 1990 to the present, and I draw a number of conclusions and suggestions from the host list and make recommendations for future research efforts.
\end{abstract}

KEY WORDS: Infection, natural host, location, particle size, prevalence, virus characterization data 
Iridoviruses are icosahedral particles that contain a double stranded DNA genome, and are assigned to one of five genera in the family Iridoviridae (Chinchar et al. 2005). Members of Ranavirus, Lymphocystivirus and Megalocytivirus infect cold-blooded vertebrates, particularly fish, amphibians and reptiles. In contrast, members of Iridovirus and Chloriridovirus infect invertebrates, mainly insects and terrestrial isopods, in damp and aquatic habitats, and are both known as invertebrate iridescent viruses (IIVs) because of the opalescent hues observed in heavily infected hosts. Such patent infections are almost invariably lethal, but there is now growing evidence that covert sublethal infections can be common in certain host species (Williams 1993, Tonka $\&$ Weiser 2000). Such covertly infected hosts can survive to the adult stage and reproduce, although covert infection is associated with extended development time, reduced adult body size and reduced fecundity and longevity (Marina et al. 1999, 2003).

Despite records of IIV infections from agriculturally and medically important species of insects, these viruses are considered to have little potential as agents of biological control due to the often low prevalence of patent disease and the broad host range displayed in laboratory tests (Ohba 1975, Henderson et al. 2001, Jakob et al. 2002). This has led to a lack of interest in the study of these viruses and a resulting paucity of information concerning their biology and survival in invertebrate populations. Indeed, the mechanisms of transmission of most IIVs remain unclear, although cannibalism and wounding have been shown to be viable mechanisms in some species (Carter 1973, Grosholz 1992, Undeen \& Fukuda 1994, Marina et al. 2005, Williams \& Hernández 2006). Nematodes and hymenopteran endoparasitoids can also transmit IIVs by introducing virus particles into susceptible hosts during the act of host penetration or oviposition, respectively (Mullens et al. 1999, López et al. 2000). Vertical transmission from parent to offspring has been demonstrated in the mosquito Ochlerotatus taeniorhynchus (Wiedemann) (Linley \& Nielsen 1968a,b; Hall \& Anthony 1971).

To accommodate the growing number of hosts reported with IIV infections, an interim system of nomenclature was proposed in which these viruses were assigned type numbers based on the chronological order in which they were reported (Tinsley \& Kelly 1970). As such, Invertebrate iridescent virus 6 (IIV-6) is the type species of the Iridovirus genus that currently comprises two species (IIV-1 and IIV-6), and eleven tentative species of interrelated viruses with a dehydrated particle diameter in the range 110-160 nm. In contrast, the type species and sole member of the genus Chloriridovirus is Invertebrate iridescent virus 3 (IIV-3), which is the most studied member of the large IIVs that have a dehydrated particle diameter in the range 170-200 nm (Chinchar et al. 2005).

In an effort to stimulate research on this intriguing, yet poorly understood group of viruses, I have generated this annotated list of reported natural host species. The list does not include laboratory host range studies that are aimed at determining taxonomic limits to virus replication and which are not usually representative of the transmission opportunities available to IIVs infecting natural host populations. Examination of the list reveals the diversity of invertebrate hosts of iridoviruses and highlights some important areas for future study.

\section{Compilation and Analysis of the Host List}

The present host list was compiled from that given in Hall (1985) and updated by searching the following online databases: Web of Science (Thompson ISI), CABI SilverPlatter abstracts, ScienceDirect (www.info. sciencedirect.com), PubMed (www.ncbi.nlm.nih.gov/entrez) and Google Scholar (scholar.google.com). The principal search terms employed were iridovirus, iridescent virus and Iridoviridae. Selected sources included those that appeared in national and international scientific journals, the great majority of which were peer-reviewed, and book chapters published by well-established editorial houses (Elsevier, CRC, Plenum, etc.). Moreover, the references cited in each report were carefully examined for evidence of additional records of invertebrate hosts.

As many of the records of IIV infections date from before the modern era of molecular virology, the criteria used for assuming a putative IIV infection were mainly based on pathology and particle morphology. Among the principal criteria for inclusion in the annotated list were (i) characteristic iridescent signs of infection observed in host tissues, particularly in the epidermis and fat body, (ii) electron microscopy (EM) observation of icosahedral particles with an electron dense core and an internal lipid membrane of the correct size range (110-200 nm diameter) located in the cell cytoplasm, (iii) evidence of DNA genome, (iv) EM studies on particle ultrastructure, stages of replication and cellular pathology, (v) serological cross-reactivity with IIV antisera, (vi) molecular genetic and sequence information (for the most recently described isolates).

For each record the following information was registered: host species, country in which the infected invertebrate was found (including State in the case of the United States), prevalence of infected individuals, particle dimensions in ultrathin section or by negative staining, the original reference and any additional information on signs and characteristics of disease, circumstances surrounding the collection (such as habitat), other infected species present at the moment of collection, taxonomic status of the virus (when appropriate), and additional references containing characterization information for the isolate in question. As there are several examples of IIVs that can naturally infect different host species, reports of infections from the same host species in different countries were listed in chronological order. In most cases, no information exists to indicate whether such records relate to strains of the same virus species or not.

\section{Invertebrate Host Diversity of Iridoviruses}

A total of 79 scientific articles were identified with original information on the occurrence of confirmed and putative IIV infections in a total of 108 invertebrate species (Table 1). The great majority of these were arthropods ( $\mathrm{N}$ 
Table 1. An annotated checklist of natural invertebrate hosts of iridoviruses.

\begin{tabular}{|c|c|c|c|c|c|}
\hline Class, order, species ${ }^{1}$ & Location & $\begin{array}{l}\text { Pre- } \\
\text { valence of } \\
\text { infection }\end{array}$ & $\begin{array}{l}\text { Particle } \\
\text { diameter } \\
(\mathrm{nm})^{2}\end{array}$ & Original reference & $\begin{array}{l}\text { Additional observations and } \\
\text { characterization references }\end{array}$ \\
\hline \multicolumn{6}{|l|}{$\begin{array}{l}\text { Insecta } \\
\text { Coleoptera }\end{array}$} \\
\hline $\begin{array}{l}\text { Costelytra zealandica } \\
\text { (White) }\end{array}$ & New Zealand & $0-10 \%$ & $130-140$ & $\begin{array}{l}\text { Kalmakoff et al. } \\
\text { (1972) }\end{array}$ & $\begin{array}{l}\text { IIV-16 is a tentative species in the } \\
\text { Iridovirus genus. Blue iridescence. } \\
\text { Infection may be covert in third } \\
\text { instars. Infected Odontria sp. also } \\
\text { reported (Moore et al. } 1974 \text {, Ward } \\
\text { \& Kalmakoff 1987, Webby \& } \\
\text { Kalmakoff 1998). }\end{array}$ \\
\hline Heteronychus arator (F.) & South Africa & 1 larva & $\begin{array}{l}120 \\
(150)\end{array}$ & $\begin{array}{l}\text { Longworth et al. } \\
\text { (1979) }\end{array}$ & $\begin{array}{l}\text { IIV-23 is a tentative species in } \\
\text { Iridovirus genus (Carey et al. 1978, } \\
\text { Williams \& Cory 1994, Webby \& } \\
\text { Kalmakoff 1998). }\end{array}$ \\
\hline Odontria striata White & New Zealand & $?$ & $?$ & $\begin{array}{l}\text { J. Kalmakoff } \\
\text { (unpublished) }\end{array}$ & $\begin{array}{l}\text { Listed as type } 19 \text { by Kelly \& } \\
\text { Robertson (1973), but in fact likely } \\
\text { to be IIV-16 (Williams \& Cory } \\
\text { 1994). }\end{array}$ \\
\hline Opogonia sp. & New Zealand & $?$ & $?$ & $\begin{array}{l}\text { Kelly \& Avery } \\
(1974)\end{array}$ & $\begin{array}{l}\text { Listed as type } 18 \text { by Kelly \& } \\
\text { Robertson (1973), but is a strain of } \\
\text { IIV-9 (Williams \& Cory 1994). }\end{array}$ \\
\hline $\begin{array}{l}\text { Phyllophaga anxia s.1. } \\
\text { (LeConte) }\end{array}$ & Canada & $1.3 \%$ & $\begin{array}{c}110 \\
(139)\end{array}$ & $\begin{array}{l}\text { Poprawski \& Yule } \\
\text { (1990) }\end{array}$ & Turquoise iridescence. \\
\hline $\begin{array}{l}\text { Popillia japonica } \\
\text { Newman }\end{array}$ & Azores & $0.01 \%$ & $(157)$ & $\begin{array}{l}\text { Lacey \& Adams } \\
(1994)\end{array}$ & $\begin{array}{l}\text { Blue iridescence. Sequence } \\
\text { information indicates similarity to } \\
\text { IIV-31 from isopods (Webby \& } \\
\text { Kalmakoff 1998). }\end{array}$ \\
\hline $\begin{array}{l}\text { Pterostichus madidus } \\
\text { (F.) }\end{array}$ & $\begin{array}{l}\text { United } \\
\text { Kingdom }\end{array}$ & ? & $?$ & $\begin{array}{l}\text { J.S. Robertson } \\
\text { (unpublished) }\end{array}$ & $\begin{array}{l}\text { Listed as type } 17 \text { by Kelly \& } \\
\text { Robertson (1973). }\end{array}$ \\
\hline $\begin{array}{l}\text { Sericesthis pruinosa } \\
\text { Dalman }\end{array}$ & Australia & 1 larva & 130 & $\begin{array}{l}\text { Steinhaus \& } \\
\text { Leutenegger (1963) }\end{array}$ & $\begin{array}{l}\text { IIV-2 is a tentative species in } \\
\text { Iridovirus genus. Blue iridescence. } \\
\text { (Williams \& Cory 1994, Webby \& } \\
\text { Kalmakoff 1998). }\end{array}$ \\
\hline Tenebrio molitor L. & $\begin{array}{l}\text { Colorado, } \\
\text { USA }\end{array}$ & $?$ & 135 & Kelly et al. (1979) & $\begin{array}{l}\text { IIV-29 is a tentative species in } \\
\text { Iridovirus genus. Infection observed } \\
\text { in laboratory colony (Black et al. } \\
\text { 1981, Williams \& Cory 1994, } \\
\text { Webby \& Kalmakoff 1998). }\end{array}$ \\
\hline
\end{tabular}

Diptera

\begin{tabular}{|c|c|c|c|c|c|}
\hline $\begin{array}{l}\text { Aedes annulipes } \\
\text { (Meigen) }\end{array}$ & $\begin{array}{l}\text { Czech } \\
\text { Republic }\end{array}$ & $<1 \%$ & $175-185$ & Weiser (1965) & $\begin{array}{l}\text { Green iridescence. Infected } A e \text {. } \\
\text { cantans also present. }\end{array}$ \\
\hline
\end{tabular}

Aedes antipodeus

(Edwards)

New Zealand ? ? Anderson (1983)

Infected $A$. subalbirostris and daphnids also present (Ward \& Kalmakoff 1991). 
Table 1. Continuation.

\begin{tabular}{|c|c|c|c|c|c|}
\hline Class, order, species ${ }^{1}$ & Location & $\begin{array}{l}\text { Pre- } \\
\text { valence of } \\
\text { infection }\end{array}$ & $\begin{array}{l}\text { Particle } \\
\text { diameter } \\
(\mathrm{nm})^{2}\end{array}$ & Original reference & $\begin{array}{l}\text { Additional observations and } \\
\text { characterization references }\end{array}$ \\
\hline \multirow{4}{*}{ Aedes cantans (Meigen) } & $\begin{array}{l}\text { Czech } \\
\text { Republic }\end{array}$ & $<1 \%$ & $175-185$ & Weiser (1965) & $\begin{array}{l}\text { Green iridescence. Infected } A e . \\
\text { annulipes also present. }\end{array}$ \\
\hline & Un. Kingdom & $<<1 \%$ & $180-185$ & Tinsley et al. (1971) & \\
\hline & Sweden & $1-2 \%$ & 150 & Popelkova (1982) & $\begin{array}{l}\text { Ae. cinereus present but not } \\
\text { infected. }\end{array}$ \\
\hline & Ukraine & $?$ & 200 & $\begin{array}{l}\text { Buchatsky \& } \\
\text { Sherban (1976) }\end{array}$ & $\begin{array}{l}\text { Blue iridescence is not consistent } \\
\text { with reported with particle size. }\end{array}$ \\
\hline \multirow{2}{*}{$\begin{array}{l}\text { Aedes caspius caspius } \\
\text { Pallas }\end{array}$} & Kazakhstan & $6 \%$ & 210 & Torybaev (1970) & $\begin{array}{l}\text { Orange iridescence. Infected larvae } \\
\text { present in about } 50 \% \text { of sites }\end{array}$ \\
\hline & Ukraine & Common & & $\begin{array}{l}\text { Buchatsky \& } \\
\text { Raikova (1978) }\end{array}$ & $\begin{array}{l}\text { sampled in August and September. } \\
\text { Tubular structures also observed in } \\
\text { cytoplasm. }\end{array}$ \\
\hline \multirow{2}{*}{ Aedes detritus (Haliday) } & France & $\sim 25 \%$ & 180 & Hassan et al. (1970) & Green iridescence. \\
\hline & Tunisia & $?$ & 180 & Vago et al. (1969) & Green or orange iridescence. \\
\hline Aedes dorsalis (Meigen) & Nevada, USA & 12 larvae & $?$ & $\begin{array}{l}\text { Chapman et al. } \\
\text { (1966) }\end{array}$ & $\begin{array}{l}\text { Green iridescence. Particles } \\
\text { observed but identity of virus not } \\
\text { confirmed. }\end{array}$ \\
\hline Aedes punctor Kirby & $\begin{array}{l}\text { Czech } \\
\text { Republic }\end{array}$ & 1 larva & $190-210$ & $\begin{array}{l}\text { Weiser \& Zizka } \\
(1985)\end{array}$ & Red iridescence. \\
\hline $\begin{array}{l}\text { Aedes stramineus } \\
\text { Dubitzky }\end{array}$ & Russia & $<1.5 \%$ & $?$ & Butchatsky (1975) & Patent infection. \\
\hline $\begin{array}{l}\text { Aedes subalbirostris } \\
\text { Klein \& Marks }\end{array}$ & New Zealand & $?$ & $?$ & Anderson (1983) & $\begin{array}{l}\text { Infected Ae. antipodeus and } \\
\text { daphnids also present (Ward \& } \\
\text { Kalmakoff 1991). }\end{array}$ \\
\hline \multirow{2}{*}{ Aedes vexans (Meigen) } & Mass., USA & $0.3 \%$ & 190 & $\begin{array}{l}\text { Hall \& Anthony } \\
\text { (1976) }\end{array}$ & Orange iridescence. \\
\hline & $\begin{array}{l}\text { Louisiana, } \\
\text { USA }\end{array}$ & $<<1 \%$ & & $\begin{array}{l}\text { Chapman et al } \\
\text { (1966) }\end{array}$ & Green iridescence. \\
\hline $\begin{array}{l}\text { Bezzia pygmaea } \\
\text { Goetghbuer }\end{array}$ & France & $1 \%$ & 130 & Rieb et al. (1982) & $\begin{array}{l}\text { Turquoise iridescence. Four } \\
\text { sympatric midge species infected. }\end{array}$ \\
\hline Chironomus plumosus L. & $\begin{array}{l}\text { Wisconsin, } \\
\text { USA }\end{array}$ & $\sim 40 \%$ & 145 & Stoltz et al. (1968) & $\begin{array}{l}\text { Infected insects did not iridesce. } \\
\text { Long fibrils observed on exterior } \\
\text { surface of virus capsid. }\end{array}$ \\
\hline $\begin{array}{l}\text { Corethrella brakeleyi } \\
\text { Coquillett }\end{array}$ & $\begin{array}{l}\text { Louisiana, } \\
\text { USA. }\end{array}$ & $0-70 \%$ & 128 & $\begin{array}{l}\text { Chapman et al. } \\
\text { (1971) }\end{array}$ & $\begin{array}{l}\text { Chaoborids predate mosquito larvae, } \\
\text { but attempts at transmission to other } \\
\text { mosquito species failed. A nematode } \\
\text { was also present at a mean } \\
\text { prevalence of } 17 \% \text {. }\end{array}$ \\
\hline \multirow[b]{2}{*}{ Culex territans Walker } & Ukraine & 24 larvae & 190 & Buchatsky (1977) & $\begin{array}{l}\text { Green iridescence. Infected larvae of } \\
\text { Culiseta annulata also present. }\end{array}$ \\
\hline & Russia & 1 pool & $?$ & Fedorova (1986) & $\begin{array}{l}\text { One pool with infected larvae out of } \\
130 \text { pools examined. Infected dixids } \\
\text { also present. }\end{array}$ \\
\hline
\end{tabular}


Table 1. Continuation.

\begin{tabular}{|c|c|c|c|c|c|}
\hline Class, order, species ${ }^{1}$ & Location & $\begin{array}{l}\text { Pre- } \\
\text { valence of } \\
\text { infection }\end{array}$ & $\begin{array}{l}\text { Particle } \\
\text { diameter } \\
\quad(n m)^{2}\end{array}$ & Original reference & $\begin{array}{l}\text { Additional observations and } \\
\text { characterization references }\end{array}$ \\
\hline Culicoides sp. & $\begin{array}{l}\text { Louisiana, } \\
\text { USA }\end{array}$ & $\begin{array}{l}100 \\
\text { larvae }\end{array}$ & $125-135$ & $\begin{array}{l}\text { Chapman et al. } \\
\text { (1968) }\end{array}$ & $\begin{array}{l}\text { Violet iridescence. Species identity } \\
\text { uncertain: either } C \text {. arboricola Root } \\
\& \text { Hoffman or C. guttipennis } \\
\text { (Coquillett). }\end{array}$ \\
\hline $\begin{array}{l}\text { Culicoides barbosai } \\
\text { Wirth \& Blanton }\end{array}$ & Florida, USA & $2.3-7.1 \%$ & 99 & Fukuda et al. (2002) & $\begin{array}{l}\text { Blue iridescence. Patent infections } \\
\text { only observed in Spring. }\end{array}$ \\
\hline $\begin{array}{l}\text { Culicoides clastrieri } \\
\text { Callot et al. }\end{array}$ & France & $1 \%$ & 130 & Rieb et al. (1982) & $\begin{array}{l}\text { Turquoise iridescence. Four } \\
\text { sympatric midge species infected. }\end{array}$ \\
\hline $\begin{array}{l}\text { Culicoides cubitalis } \\
\text { Edwards }\end{array}$ & France & $1 \%$ & 130 & Rieb et al. (1982) & $\begin{array}{l}\text { Turquoise iridescence. Four } \\
\text { sympatric midge species infected. }\end{array}$ \\
\hline $\begin{array}{l}\text { Culicoides odibilis } \\
\text { Austen }\end{array}$ & France & $1 \%$ & 130 & Rieb et al. (1982) & $\begin{array}{l}\text { Turquoise iridescence. Four } \\
\text { sympatric midge species infected. }\end{array}$ \\
\hline $\begin{array}{l}\text { Culicoides variipenis } \\
\text { sonorensis Wirth \& } \\
\text { Jones }\end{array}$ & $\begin{array}{l}\text { California, } \\
\text { USA }\end{array}$ & $1-28 \%$ & 129 & Mullens et al. (1999) & $\begin{array}{l}\text { Infection varied with instar. } \\
\text { Significant association between IIV } \\
\text { infection and a mermithid nematode. }\end{array}$ \\
\hline $\begin{array}{l}\text { Culiseta annulata } \\
\text { (Schrank) }\end{array}$ & Ukraine & 30 larvae & 180 & Buchatsky (1977) & $\begin{array}{l}\text { Violet iridescence is not consistent } \\
\text { with large particle size. Infected } \\
\text { Culex territans also present. }\end{array}$ \\
\hline Dixa sp. & Russia & Common & $?$ & Fedorova (1986) & $\begin{array}{l}\text { Turquoise iridescence. Infected } \\
\text { Culex territans also present. }\end{array}$ \\
\hline $\begin{array}{l}\text { Ochlerotatus (Aedes) } \\
\text { flavescens (Muller) }\end{array}$ & Russia & $<1.5 \%$ & ? & Butchatsky (1975) & Patent infection. \\
\hline $\begin{array}{l}\text { Ochlerotatus (Aedes) } \\
\text { fulvus pallens (Ross) }\end{array}$ & $\begin{array}{l}\text { Louisiana, } \\
\text { USA }\end{array}$ & Rare & $?$ & $\begin{array}{l}\text { Chapman et al. } \\
\text { (1966) }\end{array}$ & Green iridescence. \\
\hline $\begin{array}{l}\text { Ochlerotatus (Aedes) } \\
\text { sollicitans (Walker) }\end{array}$ & $\begin{array}{l}\text { Louisiana, } \\
\text { USA }\end{array}$ & 1 larva & 110 & $\begin{array}{l}\text { Becnel \& Fukuda } \\
\text { (1989) }\end{array}$ & $\begin{array}{l}\text { Yellow-brown iridescence is not } \\
\text { consistent with reported particle } \\
\text { size. }\end{array}$ \\
\hline $\begin{array}{l}\text { Ochlerotatus (Aedes) } \\
\text { sticticus }\end{array}$ & $\begin{array}{l}\text { Louisiana, } \\
\text { USA }\end{array}$ & 2 larvae & $?$ & $\begin{array}{l}\text { Chapman et al. } \\
\text { (1969) }\end{array}$ & Green iridescence. \\
\hline $\begin{array}{l}\text { Ochlerotatus (Aedes) } \\
\text { stimulans (Walker) }\end{array}$ & $\begin{array}{l}\text { Connecticut, } \\
\text { USA }\end{array}$ & $<1 \%$ & $135-140$ & Anderson (1970) & $\begin{array}{l}\text { Turquoise iridescence. Sympatric } \\
\text { mosquito species not patently } \\
\text { infected. }\end{array}$ \\
\hline $\begin{array}{l}\text { Ochlerotatus (Aedes) } \\
\text { taeniorhynchus } \\
\text { (Wiedemann) }\end{array}$ & $\begin{array}{l}\text { Florida, USA } \\
\text { Louisiana, } \\
\text { USA }\end{array}$ & $\begin{array}{l}0.09 \% \\
<0.5 \%\end{array}$ & 180 & $\begin{array}{l}\text { Clark et al. (1965) } \\
\text { Chapman et al. } \\
\text { (1966) }\end{array}$ & $\begin{array}{l}\text { IIV-3 is type species of the } \\
\text { Chloriridovirus genus. May be } \\
\text { vertically transmitted if infection } \\
\text { occurs shortly before pupation. } \\
\text { Regular (R) strain produces yellow- } \\
\text { green iridescence whereas } \\
\text { laboratory (L) strain produces } \\
\text { turquoise iridescence. } \\
\text { Characterization reported by } \\
\text { Wagner \& Paschke (1977) and } \\
\text { complete genome sequence by } \\
\text { Delhon et al. (2006). }\end{array}$ \\
\hline
\end{tabular}


Table 1. Continuation.

\begin{tabular}{|c|c|c|c|c|c|}
\hline Class, order, species ${ }^{1}$ & Location & $\begin{array}{l}\text { Pre- } \\
\text { valence of } \\
\text { infection }\end{array}$ & $\begin{array}{l}\text { Particle } \\
\text { diameter } \\
\qquad(\mathrm{nm})^{2}\end{array}$ & Original reference & $\begin{array}{l}\text { Additional observations and } \\
\text { characterization references }\end{array}$ \\
\hline Prosimulium sp. & Maine, USA & $2-9 \%$ & 134 & $\begin{array}{l}\text { Avery \& Bauer } \\
(1984)\end{array}$ & Blue iridescence. \\
\hline $\begin{array}{l}\text { Psorophora columbiae } \\
\text { (Dyar \& Knab) }\end{array}$ & $\begin{array}{l}\text { Louisiana, } \\
\text { USA }\end{array}$ & $?$ & $?$ & Chapman (1974) & Species given as $P$. confinnis \\
\hline $\begin{array}{l}\text { Psorophora ferox (von } \\
\text { Humboldt) }\end{array}$ & $\begin{array}{l}\text { Louisiana, } \\
\text { USA }\end{array}$ & Rare & $?$ & $\begin{array}{l}\text { Chapman et al. } \\
\text { (1966) }\end{array}$ & Blue iridescence. \\
\hline $\begin{array}{l}\text { Psorophora horrida } \\
\text { (Dyar \& Knab) }\end{array}$ & $\begin{array}{l}\text { Louisiana, } \\
\text { USA }\end{array}$ & Rare & $?$ & $\begin{array}{l}\text { Chapman et al. } \\
\text { (1969) }\end{array}$ & Blue iridescence. \\
\hline $\begin{array}{l}\text { Psorophora mathesoni } \\
\text { Belkin \& Heinemann }\end{array}$ & $\begin{array}{l}\text { Louisiana, } \\
\text { USA }\end{array}$ & 1 larva & $?$ & $\begin{array}{l}\text { Chapman et al. } \\
\text { (1969) }\end{array}$ & $\begin{array}{l}\text { Species given as } P \text {. varipes. Purple } \\
\text { iridescence. }\end{array}$ \\
\hline \multirow{2}{*}{$\begin{array}{l}\text { Simulium callidum (Dyar } \\
\& \text { Shannon) }\end{array}$} & Guatemala & $0.6-10 \%$ & $?$ & Takoaka (1980) & \multirow{2}{*}{$\begin{array}{l}\text { Prevalence of infection was highly } \\
\text { seasonal. Other infected Simulium } \\
\text { spp. present in both studies. }\end{array}$} \\
\hline & Mexico & $5.1 \%$ & $?$ & $\begin{array}{l}\text { Hernandez et al. } \\
(2000)\end{array}$ & \\
\hline $\begin{array}{l}\text { Simulium earlei Vargas } \\
\text { et al. }\end{array}$ & Guatemala & 1 larva & $?$ & Takoaka (1980) & $\begin{array}{l}\text { Other infected Simulium spp. } \\
\text { present. }\end{array}$ \\
\hline $\begin{array}{l}\text { Simulium luggeri } \\
\text { Nicholson \& Mickel }\end{array}$ & Canada & 1 larva & $?$ & $\begin{array}{l}\text { Erlandson \& Mason } \\
(1990)\end{array}$ & $\begin{array}{l}\text { Patently infected } S \text {. vittatum found } \\
\text { nearby. }\end{array}$ \\
\hline $\begin{array}{l}\text { Simulium tarsatum } \\
\text { Macquart }\end{array}$ & Mexico & $47 \%$ & $?$ & $\begin{array}{l}\text { Hernandez et al. } \\
(2000)\end{array}$ & $\begin{array}{l}\text { Species synonym of S. mexicanum. } \\
\text { Prevalence of infection was highly } \\
\text { seasonal. Other infected Simulium } \\
\text { spp. present. }\end{array}$ \\
\hline $\begin{array}{l}\text { Simulium neornatipes } \\
\text { Dumbleton }\end{array}$ & New Caledonia & a $<0.1 \%$ & 133 & Batson (1986) & Blue iridescence. \\
\hline $\begin{array}{l}\text { Simulium ochraceum } \\
\text { Walker }\end{array}$ & Mexico & $0.7 \%$ & $?$ & $\begin{array}{l}\text { Hernandez et al. } \\
(2000)\end{array}$ & $\begin{array}{l}\text { Prevalence of infection was highly } \\
\text { seasonal. Other infected Simulium } \\
\text { spp. present. }\end{array}$ \\
\hline $\begin{array}{l}\text { Simulium ornatum s.1. } \\
\text { Meigen }\end{array}$ & $\begin{array}{l}\text { Czech } \\
\text { Republic }\end{array}$ & 1 larva & $140-160$ & Weiser (1968) & Violet iridescence. \\
\hline Simulium paynei Vargas & Mexico & $2.9 \%$ & $?$ & $\begin{array}{l}\text { Hernandez et al. } \\
(2000)\end{array}$ & $\begin{array}{l}\text { Prevalence of infection was highly } \\
\text { seasonal. Other infected Simulium } \\
\text { spp. present. }\end{array}$ \\
\hline \multirow{2}{*}{$\begin{array}{l}\text { Simulium rubicundulum } \\
\text { Knab }\end{array}$} & Guatemala & $<1 \%$ & $?$ & Takoaka (1980) & \multirow{2}{*}{$\begin{array}{l}\text { Prevalence of infection was highly } \\
\text { seasonal. Other infected Simulium } \\
\text { spp. present in both studies. }\end{array}$} \\
\hline & Mexico & $13 \%$ & $?$ & $\begin{array}{l}\text { Hernandez et al. } \\
(2000)\end{array}$ & \\
\hline $\begin{array}{l}\text { Simulium variegatum } \\
\text { Meigen }\end{array}$ & $\begin{array}{l}\text { United } \\
\text { Kingdom }\end{array}$ & $0-37 \%$ & 135 & Batson et al. (1976) & $\begin{array}{l}\text { IIV-22 is a tentative species (genus } \\
\text { Iridovirus). Covert infections } \\
\text { common in Spring and Autumn } \\
\text { (Cameron 1990, Williams 1995, } \\
\text { Webby \& Kalmakoff 1998). }\end{array}$ \\
\hline $\begin{array}{l}\text { Simulium vittatum } \\
\text { Zetterstedt }\end{array}$ & Canada & $0-17 \%$ & 128 & $\begin{array}{l}\text { Erlandson \& Mason } \\
\text { (1990) }\end{array}$ & $\begin{array}{l}\text { Blue iridescence. Genome size } \sim 153 \\
\text { kbp. Infected Simulium luggeri } \\
\text { found nearby. }\end{array}$ \\
\hline
\end{tabular}


Table 1. Continuation.

\begin{tabular}{clcccc}
\hline Class, order, species ${ }^{1}$ & Location & $\begin{array}{c}\text { Pre- } \\
\text { valence of } \\
\text { infection }\end{array}$ & $\begin{array}{c}\text { Particle } \\
\text { diameter } \\
(\mathrm{nm})^{2}\end{array}$ & Original reference & $\begin{array}{l}\text { Additional observations and } \\
\text { characterization references }\end{array}$ \\
\hline Tipula paludosa Meigen & $\begin{array}{l}\text { United } \\
\text { Kingdom }\end{array}$ & $<15 \%$ & 130 & Xeros (1954) & $\begin{array}{l}\text { First IIV isolated. IIV-1 is a } \\
\text { recognized species in Iridovirus } \\
\text { genus (Smith \& Williams 1958, } \\
\text { Tajbakhsh et al. 1986, 1990). }\end{array}$ \\
Tipula sp. & $\begin{array}{l}\text { United } \\
\text { Kingdom }\end{array}$ & 1 larva & 130 & Elliott et al. (1977) & $\begin{array}{l}\text { Listed as type 25 by Tinsley \& } \\
\text { Harrap (1978). Serologically } \\
\text { indistinguishable from IIV-22. }\end{array}$
\end{tabular}

Hymenoptera

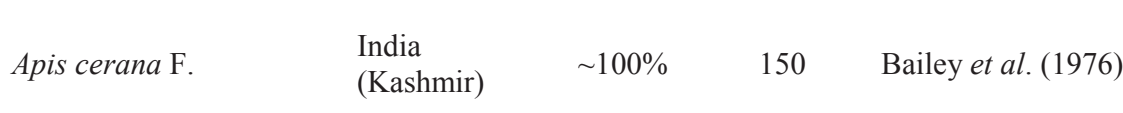

IIV-24 is a tentative species in the genus Iridovirus. Infection results in (Kashmir) "clustering" disease (Bailey \& Ball
1978, Williams \& Cory 1994, Webby \& Kalmakoff 1998).

Formica lugubris

Zetterstedt

Switzerland

Common

$120-150$

Steiger et al. (1969)

Low density of icosahedral particles in nerve and fat body cells. No patent infections seen.

Lepidoptera
Acrolophus sp.
(Acrolophidae)
California
USA
$?$
$?$
Federici (1984)

Anticarsia gemmatalis
Hübner

Argentina

Epizootic

136

Sieburth \& Carner

(1987)

Chilo suppressalis

Walker

Japan

2 larvae

160

Fukaya \& Nasu

(1966)

Malawi

1 larva

$?$

Carey et al. (1978)

(Hübner)

(20)

$\begin{array}{lllll}\begin{array}{l}\text { Helicoverpa zea } \\ \text { (Boddie) }\end{array} & \begin{array}{l}\text { Mississippi, } \\ \text { USA }\end{array} & 2-5 \% & 145 & \begin{array}{l}\text { Stadelbacher et al. } \\ (1978)\end{array} \\ \begin{array}{l}\text { Imbrasia (Gonimbrasia) } \\ \text { belina } \text { (Westwood) } \\ \text { Saturniidae }\end{array} & \begin{array}{l}\text { Southern } \\ \text { Africa }\end{array} & \text { Epizootic } & ? & \text { Knell (2006) } \\ & & & & \end{array}$

Likely to be IIV-31 as infected when breeding in association with infected isopods.

AGIV is a tentative species in Iridovirus genus (Williams 1994, Kinard et al. 1995, Webby \& Kalmakoff 1998).

IIV-6 is the type species of the genus Iridovirus (Jakob et al. 2001, Yan et al. 2000).

Listed as type 21 by Tinsely \& Harrap (1978) but now appears to have been contaminated by IIV-6 (Williams \& Cory 1994).

IIV-30 is a tentative species in Iridovirus genus. Blue iridescence. High incidence of infection by a mermithid (Hexamermis sp.) (Williams \& Cory 1994, Webby \& Kalmakoff 1998).

Believed to be an IIV due to blue iridescence of larvae. Prevalence of infection varies from year to year. 
Table 1. Continuation.

\begin{tabular}{|c|c|c|c|c|c|}
\hline Class, order, species ${ }^{1}$ & Location & $\begin{array}{l}\text { Pre- } \\
\text { valence of } \\
\text { infection }\end{array}$ & $\begin{array}{l}\text { Particle } \\
\text { diameter } \\
(\mathrm{nm})^{2}\end{array}$ & Original reference & $\begin{array}{l}\text { Additional observations and } \\
\text { characterization references }\end{array}$ \\
\hline $\begin{array}{l}\text { Spodoptera frugiperda } \\
\text { (J.E. Smith) }\end{array}$ & $\begin{array}{l}\text { Argentina } \\
\text { Mexico }\end{array}$ & $\begin{array}{c}? \\
\sim 5 \%\end{array}$ & $?$ & $\begin{array}{l}\text { Vera et al. (1995) } \\
\text { Williams \& } \\
\text { Hernandez (2006) }\end{array}$ & $\begin{array}{l}\text { Both IIV-6 like isolates (N. } \\
\text { Hernández \& T. Williams, unpubl. } \\
\text { data) }\end{array}$ \\
\hline $\begin{array}{l}\text { Wiseana cervinata } \\
\text { (Walker) }\end{array}$ & New Zealand & $\sim 30 \%$ & $135-145$ & $\begin{array}{l}\text { Fowler \& Roberston } \\
\text { (1972) }\end{array}$ & $\begin{array}{l}\text { IIV-9 is a tentative species in } \\
\text { Iridovirus genus. Blue iridescence. } \\
\text { Infected Witlesia sp. (probably } \\
\text { sabulosella) also reported (Williams } \\
\text { \& Cory 1994, Webby \& Kalmakoff } \\
\text { 1998). }\end{array}$ \\
\hline $\begin{array}{l}\text { Witlesia sabulosella } \\
\text { Meyr. }\end{array}$ & New Zealand & $\begin{array}{l}\text { Few } \\
\text { larvae }\end{array}$ & $135-145$ & $\begin{array}{l}\text { Fowler \& Roberston } \\
\text { (1972) }\end{array}$ & $\begin{array}{l}\text { Identified as a strain of IIV-9. Host } \\
\text { identity probably } W \text {. sabulosella. } \\
\text { Blue iridescence. Infected Wiseana } \\
\text { cervinata larvae also present } \\
\text { (Williams \& Cory 1994, Webby \& } \\
\text { Kalmakoff 1998). }\end{array}$ \\
\hline
\end{tabular}

\section{Orthoptera}

\begin{tabular}{|c|c|c|c|c|c|}
\hline Acheta domesticus L. & Netherlands & Common & $\begin{array}{c}(151 x \\
167)\end{array}$ & $\begin{array}{l}\text { Kleespies et al. } \\
\text { (1999) }\end{array}$ & $\begin{array}{l}\text { Commercial colony of crickets } \\
\text { infected by IIV-6 like isolate. }\end{array}$ \\
\hline $\begin{array}{l}\text { Gryllus bimaculatus De } \\
\text { Geer }\end{array}$ & Germany & Common & $\begin{array}{c}(148 x \\
172)\end{array}$ & $\begin{array}{l}\text { Just \& Essbauer } \\
\text { (2001) }\end{array}$ & $\begin{array}{l}\text { Commercial colony of crickets } \\
\text { infected by IIV-6 like isolate. }\end{array}$ \\
\hline Gryllus campestris L. & Netherlands & Common & $\begin{array}{c}(151 x \\
167)\end{array}$ & $\begin{array}{l}\text { Kleespies et al. } \\
\text { (1999) }\end{array}$ & $\begin{array}{l}\text { Commercial colony of crickets } \\
\text { infected by IIV-6 like isolate. }\end{array}$ \\
\hline $\begin{array}{l}\text { Scapteriscus borellii } \\
\text { Giglio-Tos }\end{array}$ & Brazil & $\sim 80 \%$ & $150-170$ & Fowler $(1989 a, b)$ & $\begin{array}{l}\text { Transmitted to Scapteriscus aclectus } \\
\text { and termites, Cryptotermes brevis } \\
\text { (Walker) in laboratory (Boucias et } \\
\text { al. 1987). }\end{array}$ \\
\hline
\end{tabular}

Other insect orders

Bemisia tabaci

(Gennadius)

(Homoptera)

Ecdyonurus torrentis

Kimmins

(Ephemeroptera)

Florida, USA

Czech

Republic

Common

130

(2000)

$\begin{array}{llll}\text { Ephemeropteran sp. } & \text { USA } & ? & \begin{array}{l}\text { B.A. Federici } \\ \text { (unpublished) }\end{array}\end{array}$

Hydrocyrius columbiae

columbiae Spinola

(Hemiptera)
Validity of this host record requires confirmation (Williams et al. 2005).

Infection was inapparent and sublethal.

Listed as type 26 by Tinsley \& Harap (1978) but no characterization data available.

Host identity uncertain ${ }^{3}$. Listed as type 28 but now may be contaminated by IIV-6 (Williams \& Cory 1994). 
Table 1. Continuation.

\begin{tabular}{|c|c|c|c|c|c|}
\hline Class, order, species ${ }^{1}$ & Location & $\begin{array}{l}\text { Pre- } \\
\text { valence of } \\
\text { infection }\end{array}$ & $\begin{array}{l}\text { Particle } \\
\text { diameter } \\
(\mathrm{nm})^{2}\end{array}$ & Original reference & $\begin{array}{l}\text { Additional observations and } \\
\text { characterization references }\end{array}$ \\
\hline
\end{tabular}

Crustacea

Decapoda

Acetes erythraeus Nobili Madagascar Epizootic $140 \quad$ Tang et al. (2007)

Marine. Patent infections caused local population extinction in rearing ponds whereas Penaeus monodon reared in same ponds were not affected. Partial MCP sequence indicates $80 \%$ similarity to invertebrate iridoviruses.

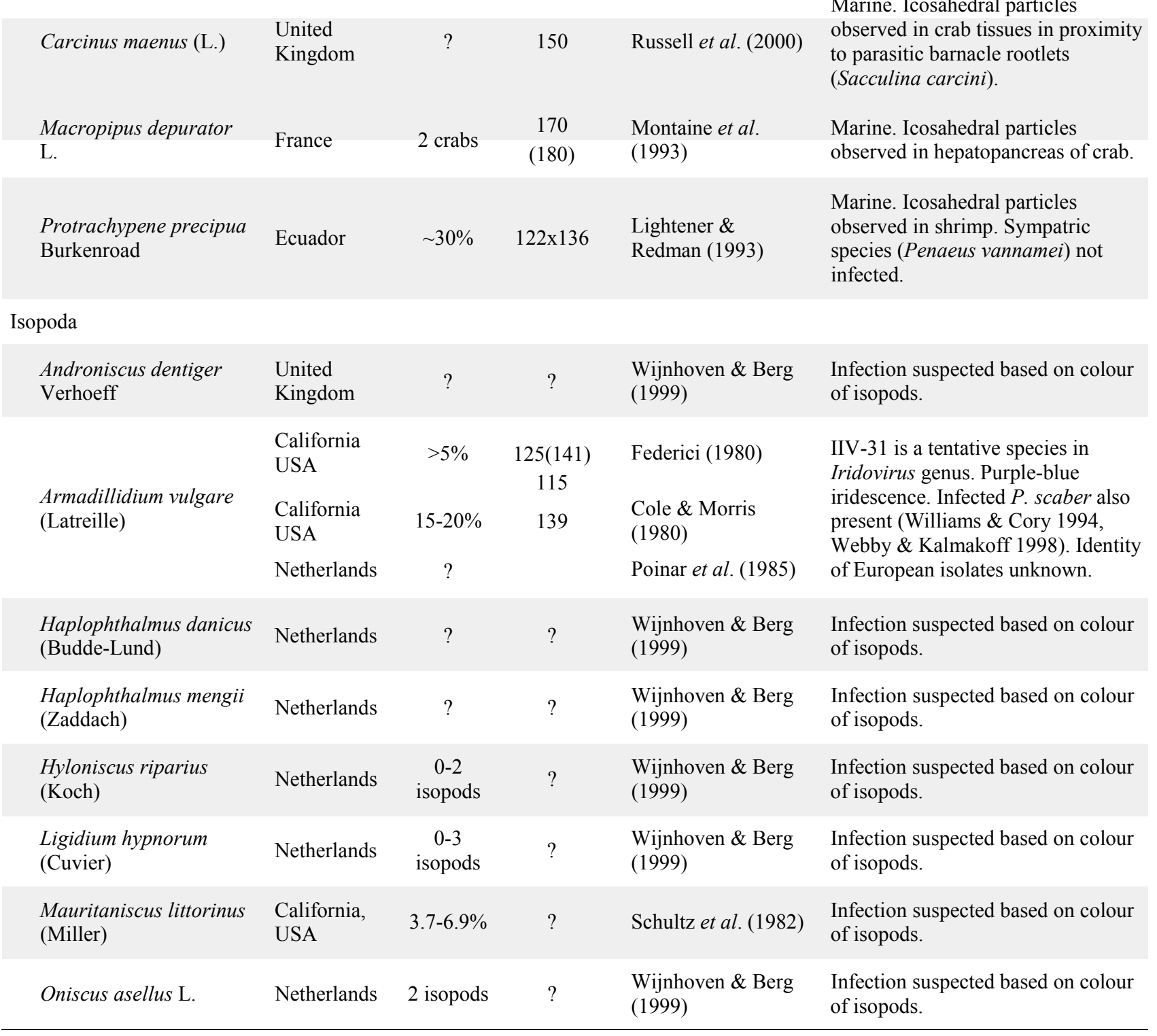


Table 1. Continuation.

\begin{tabular}{|c|c|c|c|c|c|}
\hline Class, order, species ${ }^{1}$ & Location & $\begin{array}{l}\text { Pre- } \\
\text { valence of } \\
\text { infection }\end{array}$ & $\begin{array}{l}\text { Particle } \\
\text { diameter } \\
(\mathrm{nm})^{2}\end{array}$ & Original reference & $\begin{array}{l}\text { Additional observations and } \\
\text { characterization references }\end{array}$ \\
\hline $\begin{array}{l}\text { Philoscia muscorum } \\
\text { (Scopoli) }\end{array}$ & Netherlands & $?$ & $?$ & $\begin{array}{l}\text { Wijnhoven \& Berg } \\
\text { (1999) }\end{array}$ & $\begin{array}{l}\text { Infection suspected based on colour } \\
\text { of isopods. May also exist in U.K. } \\
\text { and France. }\end{array}$ \\
\hline $\begin{array}{l}\text { Porcellio dilatatus } \\
\text { Brandt \& Ratzeburg }\end{array}$ & $\begin{array}{l}\text { California } \\
\text { USA }\end{array}$ & $>45 \%$ & $125(141)$ & Federici (1980) & $\begin{array}{l}\text { Infected by IIV- } 31 \text {. Blue } \\
\text { iridescence. Infected } A \text {. vulgare also } \\
\text { present. }\end{array}$ \\
\hline $\begin{array}{l}\text { Porcellio laevis } \\
\text { (Latreille) }\end{array}$ & $\begin{array}{l}\text { California } \\
\text { USA }\end{array}$ & $?$ & $?$ & Grosholz (1992) & $\begin{array}{l}\text { Probably infected by IIV- } 31 \\
\text { sympatric with infected } P \text {. scaber. }\end{array}$ \\
\hline \multirow{2}{*}{$\begin{array}{l}\text { Porcellio scaber } \\
\text { Latreille }\end{array}$} & $\begin{array}{l}\text { California } \\
\text { USA }\end{array}$ & $15-20 \%$ & 115 & $\begin{array}{l}\text { Cole \& Morris } \\
(1980)\end{array}$ & \multirow{2}{*}{$\begin{array}{l}\text { Purple-blue iridescence. Identical } \\
\text { strain isolated from infected } A \text {. } \\
\text { vulgare (IIV-31). Prevalence of } \\
\text { infection increases in presence of } P \text {. } \\
\text { laevis (Grosholz 1992). }\end{array}$} \\
\hline & Netherlands & $?$ & 139 & Poinar et al. (1985) & \\
\hline $\begin{array}{l}\text { Porcellio spinicornis } \\
\text { Say }\end{array}$ & Netherlands & $?$ & $?$ & $\begin{array}{l}\text { Wijnhoven \& Berg } \\
\text { (1999) }\end{array}$ & $\begin{array}{l}\text { Infection suspected based on colour } \\
\text { of isopods. May also exist in UK } \\
\text { and France. }\end{array}$ \\
\hline $\begin{array}{l}\text { Porcellionids pruinosus } \\
\text { (Brandt) }\end{array}$ & USA & $?$ & $?$ & Schultz et al. (1982) & $\begin{array}{l}\text { Infection suspected based on colour } \\
\text { of isopods. }\end{array}$ \\
\hline $\begin{array}{l}\text { Trachelipus rathkei } \\
\text { (Brandt) }\end{array}$ & USA & $?$ & $?$ & Schultz et al. (1982) & $\begin{array}{l}\text { Infection suspected based on colour } \\
\text { of isopods. }\end{array}$ \\
\hline $\begin{array}{l}\text { Trichoniscoides albidus } \\
\text { (Budde-Lund) }\end{array}$ & Netherlands & 1 isopod & $?$ & $\begin{array}{l}\text { Wijnhoven \& Berg } \\
\text { (1999) }\end{array}$ & $\begin{array}{l}\text { Infection suspected based on colour } \\
\text { of isopods. }\end{array}$ \\
\hline $\begin{array}{l}\text { Trichoniscoides } \\
\text { helveticus (Carl) }\end{array}$ & Netherlands & 2 isopods & $?$ & $\begin{array}{l}\text { Wijnhoven \& Berg } \\
\text { (1999) }\end{array}$ & $\begin{array}{l}\text { Infection suspected based on colour } \\
\text { of isopods. }\end{array}$ \\
\hline $\begin{array}{l}\text { Trichoniscus pusillus } \\
\text { Brandt }\end{array}$ & Netherlands & $\begin{array}{l}0-24 \\
\text { isopods/ } \\
\text { sample }\end{array}$ & $?$ & $\begin{array}{l}\text { Wijnhoven \& Berg } \\
\text { (1999) }\end{array}$ & $\begin{array}{l}\text { Infection suspected based on colour } \\
\text { of isopods. }\end{array}$ \\
\hline \multicolumn{6}{|l|}{ Branchiopoda (Cladocera) } \\
\hline $\begin{array}{l}\text { Ceriodaphnia dubia } \\
\text { Richard }\end{array}$ & New Zealand & $?$ & $?$ & Anderson (1983) & $\begin{array}{l}\text { Reported by Ward \& Kalmakoff } \\
\text { (1991). }\end{array}$ \\
\hline $\begin{array}{l}\text { Simocephalus expinosus } \\
\text { (Koch) }\end{array}$ & Florida, USA & $<1 \%$ & 140 & $\begin{array}{l}\text { Federici \& Hazard } \\
\text { (1975) }\end{array}$ & $\begin{array}{l}\text { Cypovirus also present in } \\
\text { population. }\end{array}$ \\
\hline
\end{tabular}

Maxillopoda (Cirripedia)
Balanus eburneus Gould
Massachusetts, ?
USA
$175 \times 222$
Leibovitz \& Koulish (1989)
Marine. Icosahedral particles observed in parenchymal cells of barnacle.

Marine. Icosahedral particles in

Sacculina carcini

United
Kingdom
150 rootlets of barnacle parasitic on crab (Carcinus maenas). 
Table 1. Continuation.

\begin{tabular}{|c|c|c|c|c|c|}
\hline Class, order, species ${ }^{1}$ & Location & $\begin{array}{l}\text { Pre- } \\
\text { valence of } \\
\text { infection }\end{array}$ & $\begin{array}{l}\text { Particle } \\
\text { diameter } \\
(\mathrm{nm})^{2}\end{array}$ & Original reference & $\begin{array}{l}\text { Additional observations and } \\
\text { characterization references }\end{array}$ \\
\hline
\end{tabular}

Other Taxa

\begin{tabular}{|c|c|c|c|c|}
\hline Crassostrea gigas ${ }^{4}$ & France & Epizootic & 380 & Comps (1970) \\
\hline $\begin{array}{l}\text { (Thunberg) } \\
\text { (Mollusca: Bivalvia) }\end{array}$ & USA & & 228 & $\begin{array}{l}\text { Comps et al. (1976) } \\
\text { Elston (1979) }\end{array}$ \\
\hline
\end{tabular}
Marine. Larger virus causes lethal infection of haemocytes (Comps \& Bonami 1977) and/or gill necrosis (Comps 1988) whereas smaller virus causes loss of velar cells and epithelial deciliation in larvae (Elston \& Wilkinson 1985).

\begin{tabular}{|c|c|c|c|c|c|}
\hline $\begin{array}{l}\text { Lymnaea truncatula } \\
\text { (Muller) ( } \\
\text { Gastropoda }\end{array}$ & France & $2-87 \%$ & $180-200$ & Barthe & $\begin{array}{l}\text { Low density of icosahedral particles } \\
\text { in amoebocytes. Prevalence varies } \\
\text { with site and season (Rondelaud \& } \\
\text { Barthe 1992). }\end{array}$ \\
\hline $\begin{array}{l}\text { Nautilus sp. } \\
\text { (Mollusca: } \\
\text { Cephalopoda) }\end{array}$ & USA & $\begin{array}{c}1 \\
\text { specimen }\end{array}$ & 176 & $\begin{array}{l}\text { Gregory et al. } \\
(2006)\end{array}$ & $\begin{array}{l}\text { Marine. Specimen died in an } \\
\text { aquarium. Sequence information } \\
\text { suggests relationship to ranaviruses. }\end{array}$ \\
\hline $\begin{array}{l}\text { Nereis diversicolor } \\
\text { Müller (Annelida: } \\
\text { Polychaeta) }\end{array}$ & France & $?$ & $160 \times 180$ & $\begin{array}{l}\text { Devauchelle \& } \\
\text { Durchon (1973) }\end{array}$ & $\begin{array}{l}\text { Marine. Purified pellets iridesce. } \\
\text { Only infects spermatocytes } \\
\text { (Devauchelle 1977). }\end{array}$ \\
\hline $\begin{array}{l}\text { Thaumamermis } \\
\text { cosgrovei Poinar } \\
\text { (Nematoda: } \\
\text { Mermithidae) }\end{array}$ & $\begin{array}{l}\text { California, } \\
\text { USA }\end{array}$ & $?$ & 135 & Poinar et al. (1980) & $\begin{array}{l}\text { Apparently acquired infection from } \\
\text { host isopod. }\end{array}$ \\
\hline $\begin{array}{l}\text { Varroa destructor } \\
\text { Anderson \& Trueman } \\
\text { (Arachnida: Acari) }\end{array}$ & USA & $?$ & 136 & $\begin{array}{l}\text { Camazine \& Liu } \\
(1998\end{array}$ & $\begin{array}{l}\text { Species described as } \\
\text { Icosahedral particles in mites from } \\
\text { moribund colony of honeybees. }\end{array}$ \\
\hline \multicolumn{6}{|c|}{$\begin{array}{l}\text { ? indicates that information is not available. } \\
1 \text { Species listed in alphabetical order. } \\
2 \text { Particle size in ultrathin section given as mean diameter in nanometres, range of diameter (a - b), or face-to-face by point- } \\
\text { point dimensions (a x b). Values from negatively stained particles are given in parentheses. } \\
3 \text { Host identity originally reported as Lethocerus columbiae but more likely to be Hydrocyrius columbiae columbiae Spinola } \\
\text { Lethocerus niloticus Stal (Villet \& Reavell 1997). } \\
4 \text { Infection causing gill disease also reported from Crassostrea angulata (Lamarck) but C. gigas and C. angulata are now } \\
\text { asidered to be the same species based on morphological, genetic and progeny hybridization data (Huvet et al. 2002). Characteristic } \\
1 \text { disease was also reported in Mytilus edulis trossulus (Gould) from the Baltic Sea near Gdansk, Poland, but the causative agent } \\
\text { s not identified (Smolarz et al. 2006). }\end{array}$} \\
\hline
\end{tabular}

$=103 ; 95 \%$ ), and the remainder were molluscs, an annelid worm and a nematode. The list included nine species from marine habitats. Of the 99 species that were not marine, 49 were from terrestrial habitats and 50 were aquatic, comprising mainly the aquatic immature stages of Diptera (44 species), nymphs of Ephemeroptera (two species), daphnids (two species) and a freshwater snail (one species).

It is intriguing to note that many records from nematocerous Diptera relate to species of Aedes, Ochlerotatus (many of which were previously classified as Aedes) and Psorophora, but there are no records for Anopheles or Uranotaenia and only a single record for Culex and Culiseta. It is likely that these occurrences reflects some aspects of the biology or ecology of these mosquitoes because species of Anopheles, Culex and Culiseta can be infected with IIV-6 in the laboratory (Fukuda 1971), but not with IIV-3, which naturally only infects the saltmarsh mosquito, O. taeniorhynchus (Woodard \& Chapman 1968).

This may be related to the survival of IIV particles in mosquito eggs (vertical transmission) as species of Aedes, Ochlerotatus and Psorophora have diapausing eggs, whereas the other genera normally do not. Alternatively, this may be due to behavioural differences as the cannibalistic habits of certain genera are an effective means of IIV transmission 
(Woodard \& Chapman 1968, Marina et al. 2005). Different genera also have distinct thermal requirements during immature development and the replication of IIVs is thermolabile with complete inhibition at temperatures over $30^{\circ} \mathrm{C}$. Finally, the turbidity of the aquatic habitat may affect the titres of suspended IIV particles which are readily adsorbed by clay particles (Christian et al. 2006), leading to sedimentation of virus particles and a reduced probability of transmission in the turbid waters inhabited by certain mosquitoes.

Another notable aspect of the host range of IIVs is that the majority of early isolates were from insects and, as such, IIVs attracted the attention of insect pathologists and were considered to be entomopathogens (Kelly 1985). However, the revision of the present list reveals that one third of the known host species are not insects. Records from terrestrial isopods (woodlice, sowbugs, pillbugs, etc.) are numerous, although the diversity of IIVs that infect them is mostly unstudied. There are also an appreciable number of records from molluscs and decapods. Comparisons of these isolates, several of which are from marine habitats, with those from insects have only been performed in two cases. In a recent record from a Nautilus sp. (Mollusca), PCR amplified DNA sequences indicated the iridovirus from this organism was more similar to those of ranaviruses than to insect iridoviruses (Gregory et al. 2006). This contrasts with a partial major capsid protein sequence recently reported from a sergestid shrimp, Acetes erythraeus, that showed $\sim 80 \%$ similarity to sequences from insect iridoviruses (Tang et al. 2007). A single report of IIV particles causing disease in reptiles (Just et al. 2001) is unprecedented and requires validation (Williams et al. 2005).

Examination of the cumulative number of scientific reports of novel hosts to IIV infections (excluding reports of marine species) over time (Fig. 1A) reveals a slightly sigmoidal tendency with a slow rate of publication in the 10-15-year period following the first report of IIV infection by Xeros (1958), followed by an increased rate of publication from 1968 to 1990 and then a slowing rate of publication from 1990 to the present. Correspondingly, the cumulative number of host species reported with confirmed or putative IIV infections over time (Fig. 1B) followed a similar trend, but with a more stepped pattern with a number of new species being reported in the late 1970's and early 1980's followed by a low rate of new reports until 1999 when several more species were reported. The current rates of publication and new species records doubtless reflect a reduction in the number of active insect pathologists in recent years and a low interest in these pathogens for biological control purposes.

\section{Geographical Distribution of Invertebrate Iridoviruses}

Species with IIV infections have been reported from every continent, except Antarctica, but there is a noticeable abundance of records from northern Europe and the United States and a paucity of records from Africa, southern Asia and Latin America (with the exception of two studies on blackflies in Mexico and Guatemala). Evidently, this reflects the distribution of insect pathologists rather than the true distribution of hosts to IIVs. The need for greater study on IIVs from these parts of the world is underlined by the case of the mopane worm, Imbrasia belina (Westwood), which is eaten for food in several countries of southern Africa and which is periodically affected by epizootics of IIV disease leading to severe economic losses (Knell 2006). Similarly, very little is known about IIV infections of the Indian honeybee, Apis cerana Fabr., that can severely affect bee colonies in southern Asia and that may interact with the parasitic mite Varroa destructor Anderson \& Trueman, (Camazine \& Liu 1998).

\section{Prevalence of Iridovirus Infections}

It is evident from the host list that in most cases, IIV infections of insects and other invertebrates are rare, with just single or small numbers of patently infected specimens present in samples of hundreds or thousands of seemingly healthy individuals. However, in the case of natural populations of blackflies and mayflies and laboratory populations of Aedes aegypti (L.), the prevalence of covert infection is between 10 and many thousands of times that of patent infections (Williams 1993, 1995; Marina 1999, 2003; Tonka \& Weiser 2000). In contrast, covert infections are rarely observed in terrestrial isopods or Spodoptera frugiperda (J. E. Smith). Clearly, IIV infection strategies and the factors that determine their virulence require considerable research. It is noticeable however, that abundant patent infections have been observed in high density populations of crickets, blackflies and some moths.

On occasions, iridovirus diseases have severely affected oyster populations in France and North America (Anthony \& Comps 1991). However, for most other marine species, putative iridovirus infections have been detected serendipitously while studying some other aspect of host biology, and most hosts showed no signs of disease.

\section{Relationship between Particle Size and Iridescence}

The genome of the chloriridovirus IIV-3 differs significantly from those of members of the Iridovirus genus (Delhon et al. 2006). However, it is uncertain whether IIVs with large diameter particles represent a distinct genetic group due to the absence of genome sequence information from large IIVs. Nonetheless, particle size is the most obvious characteristic that currently defines the two invertebrate genera. Large particles have large interparticle distances and it is the distance between planes of particles in paracrystalline arrays that creates the iridescent hues seen in patently infected hosts. As such, colour is an immediate visual indicator of approximate particle size. Violet, blue and turquoise colours are usually generated by small particles in the range 110-130 $\mathrm{nm}$ diameter (when dehydrated and measured in ultrathin section), whereas green, yellow and orange hues are likely 

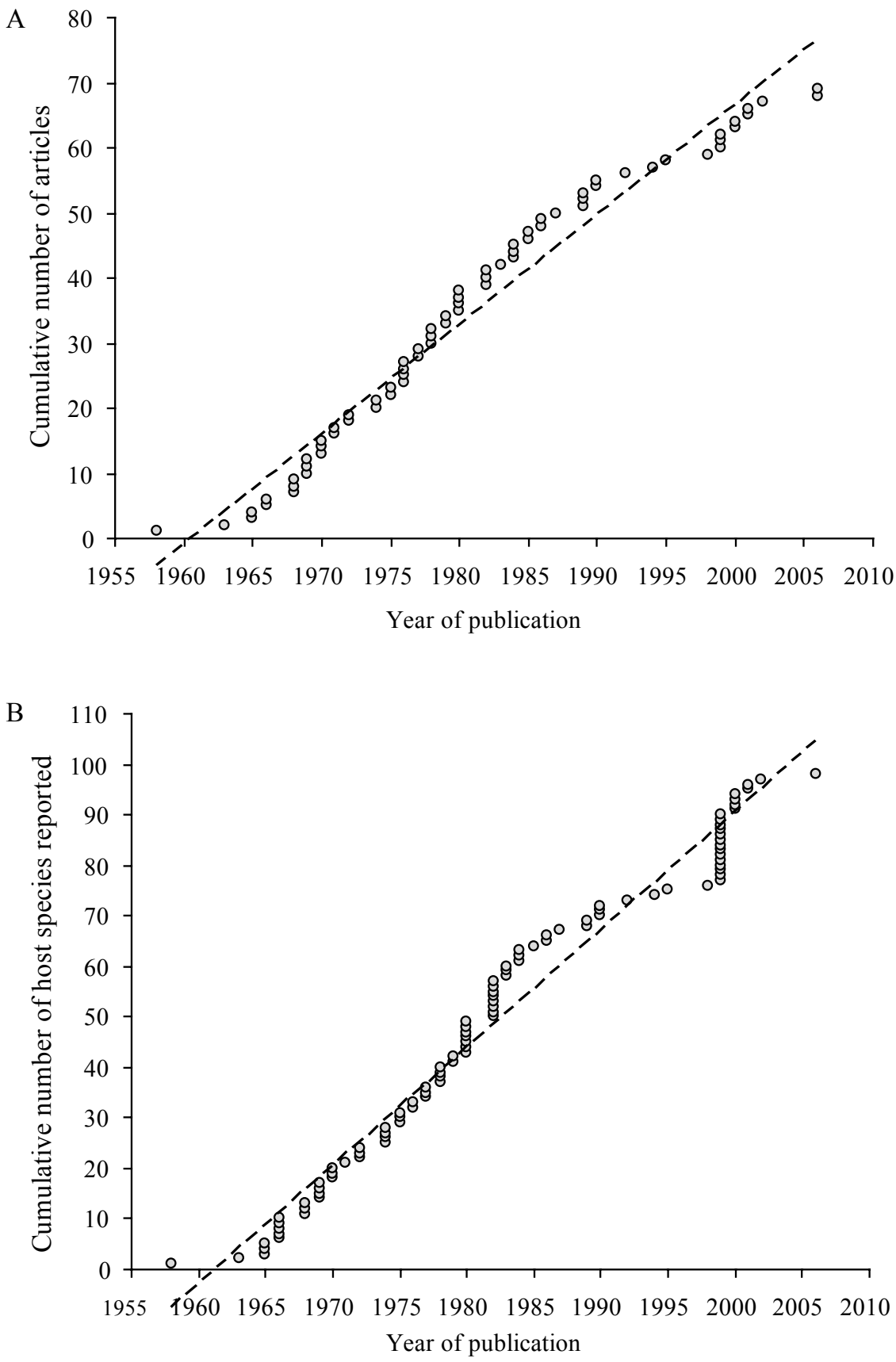

Fig. 1. Cumulative number of (A) scientific reports and (B) novel invertebrate host species to confirmed and putative iridovirus infections in the period 1958-2006. Each point represents one record or species. Dashed line indicates best fit by linear regression in Excel. Graphs do not include records of species from marine habitats.

to be seen when cells are infected with large particles (160-200 nm diameter). Light reflected from the surface of paracrystalline arrays of virus particles interferes with incident light resulting in Bragg diffraction, thus causing the iridescent hues of heavily infected hosts.

The list includes some exceptions to this principle, for example a yellow-brown infection of Ochlerotatus sollicitans (Walker) was reported to involve particles with a diameter of $110 \mathrm{~nm}$ (Becnel \& Fukuda 1989) and violet and blue infections of Culiseta annulata (Schrank) (Buchatsky 1977) and Aedes cantans (Meigen) (Buchatsky \& Sherban 1976) were reported to involve particles with diameters of 180 and $200 \mathrm{~nm}$, respectively. This can only be explained if paracrystalline arrays are unusually closely packed in the case of Cu. annulata and Ae. cantans or unusually separated in the case of $O$. sollicitans, or if measurements had been 
performed on material that had been unduly affected by laboratory processing. Indeed, the validity of using particle measurements as a key characteristic for classification has been questioned due to the variability in preparation and processing procedures between laboratories (Hall 1985).

The presence of an external fringe of fibrils that extend from the surface of the capsid can increase interparticle distance and thereby modulate the iridescence of infected hosts (Stoltz et al. 1968, Yan et al. 2000). The optical properties of IIVs have been explored using monochromatic light (Klug et al. 1959) and more recently using X-ray and thin film techniques (Juhl et al. 2004, 2006). It is notable that icosahedral particles from oysters have very large diameter particles (up to $380 \mathrm{~nm}$ ), but the genetic characteristics of these marine viruses and their relationship to IIVs from terrestrial insects are unknown.

\section{Identity of Putative Iridovirus Infections}

It is evident that the majority of IIVs lack any characterization information. Indeed, despite the abundance of records in mosquitoes and midges of medical or veterinary importance it is noticeable that virtually no characterization data exist for these isolates, with the exception of IIV-3, the genome of which has recently been entirely sequenced (Denholm et al. 2006). Moreover, of the 74 records of IIVs in insect species, only 24 have partial characterization data and only two have been subjected to complete genome sequencing (Jakob et al. 2001, Denholm et al. 2006). It is known that certain IIVs, such as IIV-9 or IIV-31, naturally infect various host species (Cole \& Morris 1980, Williams \& Cory 1994), whereas others, such as IIV-3, are believed to be restricted to single species in nature. The true natural host range of these viruses will only be determined by extensive characterization studies from a range of different host species from different habitats. This also applies to the uncharacterized viruses from marine invertebrates.

\section{Conclusions}

Examination of the host list presented here gives rise to a number of conclusions:

(i) Of the 108 species reported as natural invertebrate hosts to confirmed and putative iridovirus infections the majority (69\%) are insects or terrestrial isopods (18\%), and nine species are from marine habitats.

(ii) The most common hosts are the aquatic stages of Diptera, particularly mosquitoes, yet these infections remain extremely poorly studied. The reasons that no infections have been reported from species of Anopheles and only a single report from Culex remain unknown.

(iii) The publication rate of new host species underline the current lack of interest generated in this group of viruses despite important advances in our understanding of their survival strategies, particularly the importance of covert infections that have significant effects on a number of fitness correlates in adult insects.

(iv) Additional studies are required, specifically to elucidate the identity and host range of IIVs infecting mosquitoes and to clarify the relationship of the iridoviruses from marine hosts to the other members of this family. In particular, a greater quantity and a greater diversity of genome sequence information is needed in order to define both intraand inter-species variation in this intriguing, yet neglected, group of invertebrate viruses.

\section{Acknowledgments}

My thanks to Misha Yu. Sokolov (ECOSUR, Mexico) for careful reading of texts in Russian and Carlos F. Marina (CRISP-INSP, Mexico) for discussion of mosquito biology.

\section{References}

Anderson, J.F. 1970. An iridescent virus infecting the mosquito Aedes stimulans. J. Invertebr. Pathol. 15: 219-224.

Anderson, J.P.T. 1983. The biology and host range of a mosquito iridescent virus. Unpublished Dip. Sci. thesis, University of Otago, Dunedin, New Zealand, 216p.

Anthony, D.W. \& M. Comps. 1991. Iridoviridae, p.55-86. In J.R. Adams \& J.R. Bonami (eds.), Atlas of invertebrate viruses. Boca Raton, CRC Press, 684p.

Avery, S.W. \& L. Bauer. 1984. Iridescent virus from Prosimulium collected in Maine. J. Invertebr. Pathol. 43: 430-431.

Bailey, L. \& B.V. Ball. 1978. Apis iridescent virus and "clustering disease" of Apis cerana. J. Invertebr. Pathol. 31: 368-371.

Bailey, L., B.V. Ball \& R.D. Woods. 1976. An iridovirus from bees. J. Gen. Virol. 31: 459-461.

Barthe, D., D. Rondelaud, Y. Faucher \& C. Vago. 1984. Infection virale chez le mollusque pulmoné Lymnaea truncatula Muller. C.R. Acad. Sci. Ser. III 298: 513-515.

Batson, B.S. 1986. A small iridescent virus (Iridovirus) from Simulium neornatipes Dumbleton (Diptera: Simuliidae) in the South Pacific island of New Caledonia. J. Invertebr. Pathol. 48: 384-387.

Batson, B.S., M.R.L. Johnson, M.K. Arnold \& D.C. Kelly. 1976. An iridescent virus from Simulium sp. (Diptera: Simuliidae) in Wales. J. Invertebr. Pathol. 27: 133-135.

Becnel, J.J. \& T. Fukuda. 1989. Natural occurrence of a mosquito iridescent virus in Aedes sollicitans. J. Am. Mosq. Contr. Assoc. 5: 610-611.

Black, P.N., C.D. Blair, A. Butcher, J.L. Capinera \& G.M. Happ. 1981. Biochemistry and ultrastructure of iridescent virus type 29. J. Invertebr. Pathol. 38: 12-21.

Boucias, D.G., J.E. Maruniak \& J.C. Pendland. 1987. Characterization of an iridovirus isolated from the southern mole cricket, Scapteriscus vicinus. J. Invertebr. Pathol. 50: 238-245.

Buchatsky, L.P. 1975. Viruses pathogenic for mosquitoes (Diptera, Culicidae). Voprosy Virusologii 3: 268-273 (in Russian). 
Buchatsky, L.P. 1977. An iridovirus from larvae of Culiseta annulata and Culex territans. Acta Virol. 21: 85-86.

Buchatsky, L.P. \& A.P. Raikova. 1978. Study of Aedes caspius caspius mosquito larvae affested with iridescence virus. Voprosy Virusologii 3: 366-369 (in Russian).

Buchatsky, L.P. \& S.D. Sherban. 1976. Some biological properties of Aedes cantans iridescence virus. Voprosy Virusologii 4: 432-435 (in Russian).

Camazine, S. \& T.P. Liu. 1998. A putative iridovirus from the honey bee mite Varroa jacobsoni Oudemans. J. Invertebr. Pathol. 71: 177-178.

Cameron, I.R. 1990. Identification and characterization of the gene encoding the major structural protein of insect iridescent virus type 22. Virology 178: 35-42.

Carey, G.P., T. Lescott, J.S. Robertson, L.K. Spencer \& D.C. Kelly. 1978. Three African isolates of small iridescent viruses: Type 21 from Heliothis armigera (Lepidoptera: Noctuidae), type 23 from Heteronychus arator (Coleoptera: Scarabaeidae), and type 28 from Lethocerus columbiae (Hemiptera, Heteroptera: Belostomatidae). Virology 85: 307-309.

Carter, J.B. 1973. The mode of transmission of Tipula iridescent virus. II Route of infection. J. Invertebr. Pathol. 21: 136143.

Chapman, H.C. 1974. Biological control of mosquito larvae. Annu. Rev. Entomol. 19: 33-59.

Chapman, H.C., J.J. Petersen, D.B. Woodard \& T.B. Clark. 1968. New records of parasites of Certopogonidae. Mosq. News 28: $122-123$.

Chapman, H.C., T.B. Clark, D.B. Woodard \& W.R. Kellen. 1966. Additional mosquito hosts of the mosquito iridescent virus. J. Invertebr. Pathol. 8: 545-546.

Chapman, H.C., T.B. Clark, D.W. Anthony \& F.E. Glenn. 1971. An iridescent virus from larvae of Corethrella brakeleyi (Diptera: Chaoboridae) in Louisiana. J. Invertebr. Pathol. 18: 284-286.

Chapman, H.C., T.B. Clark, J.J. Petersen \& D.B. Woodard. 1969. A two-year survey of pathogens and parasites of Culicidae, Chaoboridae, and Ceratopogonidae in Louisiana. Proc. 56th Annu. Meet. N.J. Mosq. Exterm. Assoc. p.203-212.

Chinchar, V.G., S. Essbauer, J.G. He, A. Hyatt, T. Miyazaki, V. Seligy \& T. Williams. 2005. Iridoviridae, p. 163-175. In C.M. Fauquet, M.A. Mayo, J. Maniloff, U. Desselberger, \& L.A. Ball (eds.), Virus taxonomy: 8th Report of the International Committee on the Taxonomy of Viruses. London, Elsevier, $1259 \mathrm{p}$.

Christian, P., A.R. Richards \& T. Williams. 2006. Differential adsorption of occluded and non-occluded insect pathogenic viruses to soil forming minerals. Appl. Environ. Microbiol. 72: 4648-4652.

Clark, T.B., W.R. Kellen \& P.T.M. Lum. 1965. A mosquito iridescent virus (MIV) from Aedes taeniorhynchus (Wiedemann). J. Invertebr. Pathol. 7: 519-521.

Cole, A., \& T.J. Morris. 1980. A new iridovirus of two species of terrestrial isopods, Armadillidium vulgare and Porcellio scaber. Intervirol. 14: 21-30.

Comps, M. 1970. La maladie des branchies chez les huitres du genre Crassostrea, caractéristique et évolution des altérations, processus de cicatrisation. Rev. Trav. Inst. Pêches Marit. 34: 23-44.

Comps, M. 1988. Epizootic diseases of oysters associated with viral infections. Amer. Fish. Soc. Special Public. 18: 23-37.

Comps, M. \& J.R. Bonami. 1977. Infection virale associée a des mortalites chez l'huitre Crassostrea gigas Th. C. R. Acad. Sci. Paris Ser. D. 285: 1139-1140.

Comps, M., J.R. Bonami, C. Vago \& A. Campillo. 1976. Une virose de l'huître portugaise (Crassostrea angulata). C. R. Acad. Sci. Paris Ser. D. 282: 1991-1993.

Delhon, G., E.R. Tulman, C.L. Afonso, Z. Lu, J.J. Becnel, B.A. Moser, G.F. Kutish \& D.L. Rock. 2006. Genome of Invertebrate iridescent virus type 3 (mosquito iridescent virus). J. Virol. 80: 8439-8449.

Devauchelle, G. 1977. Ultrastructural study of an iridovirus from the marine worm Nereis diversicolor (O.F. Muller). J. Invertebr. Pathol. 81: 237-246.

Devauchelle, G. \& M. Durchon. 1973. Sur la presence d'un virus e type iridovirus dans les cellules males de Nereis diversicolor (O.F. Muller). C.R. Acad. Sci. Paris Ser. D 277: 463-466.

Elliott, R.M., T. Lescott \& D.C. Kelly. 1977. Serological relationships of iridescent virus type 25. Virology 81: 309-316.

Elston, R. 1979. Virus-like particles associated with lesions in larval Pacific oysters (Crassostrea gigas). J. Invertebr. Pathol. 33: 71-74.

Elston, R.A. \& M.T. Wilkinson. 1985. Pathology, management and diagnosis of oyster velar virus disease (OVVD). Aquaculture 48: $189-210$.

Erlandson, M.A. \& P.G. Mason. 1990. An iridescent virus from Simulium vittatum (Diptera: Simuliidae) in Saskatchewan. J. Invertebr. Pathol. 56: 8-14.

Federici, B.A. 1980. Isolation of an iridovirus from two terrestrial isopods, the pill bug, Armadillidium vulgare and the sow bug, Porcellio dilatatus. J. Invertebr. Pathol. 36: 373-381.

Federici, B.A. 1984. Diseases of terrestrial isopods. Symp. Zool. Soc. Lond. 53: 233-245.

Federici, B.A. \& E.I. Hazard. 1975. Iridovirus and cytoplasmic polyhedrosis virus in the freshwater daphnid Simocephalus expinosus. Nature 254: 327-328.

Fedorova, V.G. 1986. On finding larvae of Culex territans Walk. and Dixidae infected with iridovirus in the forest zone of Novgorrod region. Med. Parazitol. Mosk. 3: 86-87 (in Russian).

Fowler, H.G. 1989a. An epizootic iridovirus of Orthoptera (Gryllotalpidae: Scaptericus borellii) and its pathogenicity to termites (Isoptera: Cryptotermes). Rev. Microbiol. São Paulo 20: $115-120$

Fowler, H.G. 1989b. Controle microbiano natural de populações de 
paquinhas (Orthoptera: Gryllotalpidae: Scapteristcus borellii): regulação de populações agregadas no tempo e no espaço. Rev. Bras. Biol. 49: 1039-1051.

Fowler, M. \& J.S. Robertson. 1972. Iridescent virus infection in field populations of Wiseana cervinata (Lepidoptera: Hepialidae) and Witlesia sp. (Lepidoptera: Pyralidae) in New Zealand. J. Invertebr. Pathol. 19: 154-155.

Fukaya, M. \& S. Nasu. 1966. A Chilo iridescent virus (CIV) from the rice stem borer Chilo suppressalis Walker (Lepidoptera: Pyralidae). Appl. Entomol. Zool. 1: 69-72.

Fukuda, T. 1971. Per os transmission of Chilo iridescent virus to mosquitoes. J. Invertebr. Pathol. 18: 152-153.

Fukuda, T., D.L. Kline \& J.F. Day. 2002. An iridescent virus and a microsporidium in the biting midge Culicoides barbosai from Florida. J. Amer. Mosq. Contr. Assoc. 18: 128-130.

Gregory, C.R., K.S. Latimer, K.E. Pennick, K. Benson \& T. Moore. 2006. Novel iridovirus in a nautilus (Nautilus spp.). J. Vet. Diagn. Invest. 18: 208-211.

Grosholz, E.D. 1992. Interactions of intraspecific, interspecific and apparent competition with host-pathogen population dynamics, Ecology 73: 507-514.

Hall, D.W. 1985. Pathobiology of invertebrate icosahedral cytoplasmic deoxyriboviruses (Iridoviridae), p.163-196. In K. Maramorosh \& K.E. Sherman (eds.), Viral insecticides for biological control. New York, Academic Press, 581p.

Hall, D.W. \& D.W. Anthony. 1971. Pathology of a mosquito iridescent virus (MIV) infecting Aedes taeniorhynchus. J. Invertebr. Pathol. 18: 61-69.

Hall, D.W. \& D.W. Anthony. 1976. An "R" type iridovirus from Aedes vexans (Meigen). Mosq. News 36: 536-537.

Hasan, S., G. Croizier, C. Vago \& J.L. Duhoit. 1970. Infection a virus irisant dans une population naturelle d'Aedes detritus Haliday en France. Ann. Zool. Ecol. Anim. 2: 295-299.

Henderson, C.W., C.L. Johnson, S.A. Lodhi \& S.L. Bilimoria. 2001. Replication of Chilo iridescent virus in the cotton boll weevil, Anthonomus grandis, and development of an infectivity assay. Arch. Virol. 146: 767-775.

Hernández, O., G. Maldonado \& T. Williams. 2000. An epizootic of patent iridescent virus disease in multiple species of blackflies in Chiapas, Mexico. Med. Vet. Entomol. 14: 458-462.

Hunter, W.B., C.P. Patte, X.H. Sinisterra, D.S. Achor, C.J. Funk \& J.E. Polston. 2001. Discovering new insect viruses: Whitefly iridovirus (Homoptera: Aleyrodidae: Bemisia tabaci). J. Invertebr. Pathol. 78: 220-225.

Huvet, A., A. Gérard, C. Ledu, P. Phélipot, S. Heurtebise \& P. Boudry. 2002. Is fertility of hybrids enough to conclude that the two oysters Crassostrea gigas and Crassostrea angulata are the same species? Aquat. Living Resour. 15: 45-52.

Jakob, N.J., K. Muller, U. Bahr \& G. Darai. 2001. Analysis of the first complete DNA sequence of an invertebrate iridovirus: coding strategy of the genome of Chilo iridescent virus. Virology 286: 182-196.
Jakob, N.J., R.G. Kleespies, C.A. Tidona, K. Müller, H.R. Gelderblom \& G. Darai. 2002. Comparative analysis of the genome and host range characteristics of two insect iridoviruses: Chilo iridescent virus and a cricket iridovirus isolate. J. Gen. Virol. 83: 463-470.

Juhl, S.B, E.P. Chan, Y.H. Ha, M. Maldovan, J. Brunton, V. Ward, T. Dokland, J. Kalmakoff, B. Farmer, E.L. Thomas \& R.A. Vaia. 2006. Assembly of Wiseana iridovirus: viruses for colloidal photonic crystals. Adv. Func. Mat. 16: 1086-1094.

Juhl, S.,Y.H. Ha, E. Chan, V. Ward, A. Smith, T. Dokland, E.L. Thomas \& R. Vaia. 2004. Bioharvesting: Optical characteristics of Wiseana iridovirus assemblies. Polymer. Mat. Sci. Eng. 90: 317-318.

Just, F.T. \& S.S. Essbauer. 2001. Characterization of an iridescent virus isolated from Gryllus bimaculatus (Orthoptera: Gryllidae). J. Invertebr. Pathol. 77: 51-61.

Just, F., S. Essbauer, W. Ahne \& S. Blahak. 2001. Occurrence of an invertebrate iridescent-like virus (Iridoviridae) in reptiles. J. Vet. Med. B 48: 685-694.

Kalmakoff, J., S. Moore \& R.P. Pottinger. 1972. An iridescent virus from the grass grub Costelytra zealandica: Serological study. J. Invertebr. Pathol. 20: 70-76.

Kelly, D.C. 1985. Insect iridescent viruses. Curr. Top. Microbiol. Immunol. 116: 23-35.

Kelly, D.C. \& J.S. Robertson. 1973. Icosahedral cytoplasmic deoxriboviruses. J. Gen. Virol. (Suppl.) 20: 17-41.

Kelly, D.C., M.D. Ayres, T. Lescott, J.S. Robertson \& G.M. Happ. 1979. A small iridescent virus (type 29) isolated from Tenebrio molitor: A comparison of its proteins and antigens with six other iridescent viruses. J. Gen. Virol. 42: 95-105.

Kelly, D.C. \& R.J. Avery. 1974. The DNA content of four small iridescent viruses: genome size, redundancy and homology determined by renaturation kinetics. Virology 57: 425-435.

Kinard, G.R., O.W. Barnett \& G.R. Carner. 1995. Characterization of an iridescent virus isolated from the velvetbean caterpillar, Anticarsia gemmatalis. J. Invertebr. Pathol. 66: 258-263.

Kleespies, R.G., C.A. Tidona \& G. Darai. 1999. Characterization of a new iridovirus isolated from crickets and investigations on the host range. J. Invertebr. Pathol. 73: 84-90.

Klug, A., R.E. Franklin \& S.P.F. Humphreys-Owen. 1959. The crystal structure of Tipula iridescent virus as determined by Bragg reflection of visible light. Biochim. Biophys. Acta 32: 203-219.

Knell, R. 2006. Mopane worm diseases, p.119. In J. Ghazoul (ed.), Mopane woodlands and the mopane worm: Enhancing rural livelihoods and resource sustainability. Final Technical Report to Department of Funding International Development, Forestry Research Programme, project number R 7822, London.

Lacey, L.A. \& J.R. Adams. 1994. An iridescent virus from Popillia japonica (Col., Scarabaeidae). Entomophaga 39: 131-136.

Leibovitz, L. \& S. Koulish. 1989. A viral disease of the ivory barnacle Balanus eburneus Gould (Crustacea, Cirripedia). Biol. 
Bull. Woods Hole Mar. Biol. Lab. 176: 301-307.

Lightner, D.V. \& R.M. Redman. 1993. A putative iridovirus from the penaeid shrimp Protrachypene precipua Burkenroad (Crustacea: Decapoda). J. Invertebr. Pathol. 62: 107-109.

Linley, J.R. \& H.T. Nielsen. 1968a. Transmission of a mosquito iridescent virus in Aedes taeniorhynchus. I. Laboratory experiments. J. Invertebr. Pathol. 12: 7-16.

Linley, J.R. \& H.T. Nielsen. 1968b. Transmission of a mosquito iridescent virus in Aedes taeniorhynchus. II. Experiments related to transmission in nature. J. Invertebr. Pathol. 12: 17-24.

Longworth, J.F., P.D. Scotti \& R.D. Archibald. 1979. An iridovirus from the black beetle Heteronychus arator (Coleoptera: Scarabaeideae). N.Z. J. Zool. 6: 637-639.

López, M., J. C. Rojas, R. Vandame \& T. Williams. 2002. Parasitoidmediated transmission of an iridescent virus. J. Invertebr. Pathol. 80: 160-170.

Marina, C.F., I. Fernández-Salas, J.E. Ibarra, J.I. ArredondoJiménez, J. Valle \& T. Williams. 2005. Transmission dynamics of an iridescent virus in an experimental mosquito population: the role of host density. Ecol. Entomol. 30: 376-382.

Marina, C.F., J. Arredondo-Jiménez, A. Castillo \& T. Williams. 1999. Sublethal effects of iridovirus disease in a mosquito. Oecologia 119: 383-388.

Marina, C.F., J.E. Ibarra, J.I. Arredondo-Jiménez, I. FernándezSalas, P. Liedo \& T. Williams. 2003. Adverse effects of covert iridovirus infection on life history and demographic parameters of Aedes aegypti. Entomol. Exp. Appl. 106: 53-61.

Montanie, H., J.R. Bonami \& M. Comps. 1993. Irido-like virus infection in the crab Macropipus depurator L. (Crustacea: Decapoda). J. Invertebr. Pathol. 61: 320-322.

Moore, S.G., J. Kalmakoff \& J.A.R. Miles. 1974. An iridescent virus and a rickettsia from the grass grub Costelytra zealandia (Coleoptera: Scarbaeidae). N.Z. J. Zool. 1: 205-210.

Mullens, B.A., R.K. Velten \& B.A. Federici. 1999. Iridescent virus infection in Culicoides variipennis sonorensis and interactions with the mermithid parasite Heleidomermis magnapapula. J. Invertebr. Pathol. 73: 231-233.

Ohba, M. 1975. Studies on the parthogenesis of Chilo iridescent virus. 3. Multiplication of CIV in the silkworm Bombyx mori L. and field insects. Sci. Bull. Fac. Agr. Kyushu Univ. 30: 71-81 (in Japanese).

Poinar Jr., G.O., R.T. Hess \& A. Cole. 1980. Replication of an iridovirus in a nematode (Mermithidae). Intervirol. 14: 316320 .

Poinar Jr., G.O., R.T. Hess \& J.H. Stock. 1985. Occurrence of the isopod iridovirus in European Armadillidium and Porcellio (Crustacea: Isopoda). Bijdrag. Tot Dierkun. 55: 280-282.

Popelkova, Y. 1982. Coelomomyces from Aedes cinereus and a mosquito iridescent virus of Aedes cantans in Sweden. J. Invertebr. Pathol. 40: 148-149.
Poprawski, T.J. \& W.N. Yule. 1990. A new small iridescent virus from grubs of Phyllophaga anxia (LeConte) (Col., Scarabaeidae). J. Appl. Entomol. 110: 63-67.

Rieb, J.P., E. Mialhe \& J.M. Quiot. 1982. Ceratopogonidae larvae infected by an iridovirus. Mosq. News 42: 529.

Rondelaud, D. \& D. Barthe. 1992. Observations epidemiologiques sur l'iridovirose de Lymnaea truncatula, mollusque vecteur de Fasciola hepatica. C.R. Acad. Sci. Paris Ser. III 314: 609-612.

Russell, J.D., G. Walker \& R. Woollen. 2000. Observations on two infectious agents found within the rootlets of the parasitic barnacle Sacculina carcini. J. Mar. Biol. Assoc. U.K. 80: 373-374.

Schultz, G.A., R.L. Garthwaite \& C. Sassaman. 1982. A new family placement for Mauritaniscus littorinus (Miller) N. Comb. from the west coast of North America with ecological notes (Crustacea: Isopoda: Oniscoidea: Bathytropidae). Wasmann J. Biol. 40: 77-89.

Sieburth, P.J. \& G.R. Carner. 1987. Infectivity of an iridescent virus for larvae of Anticarsia gemmatalis (Lepidoptera: Noctuidae). J. Invertebr. Pathol. 49: 49-53.

Smith, K.M. \& R.C. Williams. 1958. Insect viruses and their structure. Endeavour 17: 12-21.

Smolarz, K., M. Wolowicz \& M. Stachnik. 2006. First record of the occurrence of ,gill disease" in Mytilus edulis trossulus from the Gulf of Gdansk (Baltic Sea, Poland). J. Invertebr. Pathol. 93: 207-209.

Stadelbacher, E.A., J.R. Adams, R.M. Faust \& G.J. Tompkins. 1978. An iridescent virus of the bollworm Heliothis zea (Lepidoptera: Noctuidae). J. Invertebr. Pathol. 32: 71-76.

Steiger, U., H.E. Lamparter, C. Sandri \& K. Akert. 1969. Virusähnliche partikel im zytoplasma von nerven und gliazellen der waldameise. Arch. Ges. Virusforsch. 26: 271-282.

Steinhaus, E.A. \& R. Leutenegger. 1963. Icosahedral virus from a scarab (Sericesthis). J. Insect Pathol. 5: 266-270.

Stoltz, D.B., W.L. Hilsenhoff \& H.F. Stich. 1968. A virus disease of Chironomus plumosus. J. Invertebr. Pathol. 12: 118-128.

Tajbakhsh, S., M.J. Dove, P.E. Lee \& V.L. Seligy. 1986. DNA components of Tipula iridescent virus. Biochem. Cell. Biol. 64: 495-503.

Tajbakhsh, S., P.E. Lee, D.C. Watson \& V.L. Seligy. 1990. Molecular cloning and expression of the Tipula iridescent virus capsid gene. J. Virol. 64: 125-136.

Takoaka, H. 1980. Pathogens of blackfly larvae in Guatemala and their influence on natural populations of three species of onchocercosis vectors. Am. J. Trop. Med. Hyg. 29: 467-472.

Tang, K.F.J., R.M. Redman, C.R. Pantoja, M. Le Groumellec, P. Duraisamy \& D.V. Lightner. 2007. Identification of an iridovirus in Acetes erythraeus (Sergestidae) and the development of in situ hybridization and PCR method for its detection. J. Invertebr. Pathol. 96: 255-260. 
Tinsley, T.W. \& D.C. Kelly. 1970. An interim nomenclature system for the iridescent group of viruses. J. Invertebr. Pathol. 12: 66-68.

Tinsley, T.W. \& J.A. Harrap. 1978. Viruses of invertebrates, p.1-101. In H. Fraenkel-Conrat \& R.R. Wagner (eds.), Comprehensive virology, v. 12, New York, Plenum Press, 312p.

Tinsley, T.W., J.S. Robertson, C.F. Rivers \& M.W. Service. 1971. An iridescent virus of Aedes cantans in Great Britain. J. Invertebr. Pathol. 18: 427-428.

Tonka, T. \& J. Weiser. 2000. Iridovirus infection in mayfly larvae. J. Invertebr. Pathol. 76: 229-231.

Torybaev, K.K. 1970. Discovery of orange iridescent virus of mosquito in the larvae of Aedes caspius caspius in the southeastern part of Kazakhstan. Vestn. Acad. Nauk. Kaz. S.S.R. 7: 68-69 (in Russian).

Undeen, A.H. \& T. Fukuda. 1994. Effects of host resistance and injury on the susceptibility of Aedes taeniorhynchus to mosquito iridescent virus. J. Am. Mosq. Contr. Assoc. 10: 64-66.

Vago C., J.A. Rioux, J.L. Duthoit \& J.P. Dedet. 1969. Infection spontanée à virus irisant dans une population d'Aedes detritus (Hal., 1833) des environs de Tunis. Ann. Parasitol. (Paris) 44: 667-676.

Vera, M.L., L. Valverde, S.B. Popich \& Z.D. Ajmat de Toledo. 1995. Evaluación preliminar de los enemigos naturales de Spodoptera frugiperda (J.E. Smith) (Lepidoptera: Noctuidae) en Tucumán, Argentina. Acta Entomol. Chilena 19: 135-141.

Villet, M.H. \& P. Reavell. 1997. The water bugs (Hemiptera: Gerromorpha, Nepomorpha and Leptopodomorpha) of South Africa. Online: ru.ac.za/academic/departments/zooento/ Martin/hydrocorisae.html. Acessed in: 26 November 2008.

Wagner, G.W. \& J.D. Paschke. 1977. A comparison of the DNA of $\mathrm{R}$ and $\mathrm{T}$ strains of mosquito iridescent virus. Virology 81: 298-308

Ward, V.K. \& J. Kalmakoff. 1987. Physical mapping of the DNA genome of insect iridescent virus type 9 from Wiseana spp. larvae. Virology 160: 507-510.

Ward, V.K. \& J. Kalmakoff. 1991. Invertebrate Iridoviridae, p.197226. In E. Kurstak (ed.), Viruses of invertebrates. New York, Marcel Dekker, 351p.
Webby, R. \& J. Kalmakoff. 1998. Sequence comparison of the major capsid protein gene from 18 diverse iridoviruses. Arch. Virol. 143: 1949-1966.

Weiser, J. 1965. A new virus infection of mosquito larvae. Bull. W.H.O. 33: 586-588.

Weiser, J. 1968. Iridescent virus from the blackfly Simulium ornatum Meigen in Czechoslovakia. J. Invertebr. Pathol. 12: 36-39.

Weiser, J. \& Z. Zizka. 1985. A red mosquito iridescent virus in Aedes punctor in Czechoslovakia. Folia Parasitol. 32: 285-287.

Wijnhoven, H. \& M.P. Berg. 1999. Some notes on the distribution and ecology of iridovirus (Iridovirus, Iridoviridae) in terrestrial isopods (Isopoda, Oniscidae). Crustaceana 72: 145-156.

Williams, T. 1993. Covert iridovirus infection of blackfly larvae. Proc. R. Soc. Ser. B. Biol. Sci. 251: 225-230.

Williams, T. 1994. Comparative studies of iridoviruses: Further support for a new classification. Virus Res. 33: 99-121.

Williams, T. 1995. Patterns of covert infection by invertebrate pathogens: Iridescent viruses of blackflies. Mol. Ecol. 4: 447-457.

Williams, T. \& J.S. Cory. 1994. Proposals for a new classification of iridescent viruses. J. Gen. Virol. 75: 1291-1301.

Williams, T. \& O. Hernández. 2006. Costs of cannibalism in the presence of an iridovirus pathogen of Spodoptera frugiperda. Ecol. Entomol. 31: 106-113.

Williams, T., V. Barbosa-Solomieu \& V.G. Chinchar. 2005. A decade of advances in iridovirus research. Adv. Virus Res. 65: $173-248$.

Woodard, D.B. \& H.C. Chapman. 1968. Laboratory studies with the mosquito iridescent virus (MIV). J. Invertebr. Pathol. 11: 296-301.

Xeros, N. 1954. A second virus disease of the leather-jacket, Tipula paludosa. Nature 174: 562563.

Yan, X., N.H. Olson, J.L. Van Etten, M. Bergoin, M.G. Rossmann \& T.S. Baker. 2000. Structure and assembly of large lipidcontaining dsDNA viruses. Nature Struct. Mol. Biol. 7: 101-103.

Received 30/VIII/06. Accepted 24/X/08. 